\title{
ANALISIS FAKTOR-FAKTOR PENENTU EMPLOYEE ENGAGEMENT DI PT. ABC BANDUNG
}

\author{
Ni Putu Irma Mei Lina ${ }^{1 *}$, Anita Silvianita² \\ 1,2,3Universitas Telkom, Bandung - Indonesia
}

\section{A R T I C L E I N F O}

\section{Article history:}

Received 04 April 2019

Received in revised form 04 Mey 2019

Accepted 05 December 2019

Available online 11

December 2019

\section{Kata Kunci:}

Analisis Faktor, Employee Engagement, Lingkungan Kerja

Keywords:

Factor Analysis, Employee Engagement, Work

Environment

\section{A B S T R A K}

Employee engagement merupakan wujud loyalitas karyawan terhadap perusahaan. Penelitian ini dilakukan di PT. ABC Bandung. Terdapat indikasi bahwa adanya tingkat employee engagement yang tinggi pada karyawan PT. ABC Bandung. Penelitian ini bertujuan untuk mengetahui faktor- faktor penentu employee engagement karyawan di PT. $\mathrm{ABC}$ Bandung. Faktor-faktor employee engagement pada penelitian ini merujuk pada hasil penelitian yang dikemukakan oleh Anitha (2014) dengan landasan teori dari Elliott dan Corey (2018:13). Pada penelitian Anitha (2014) terdapat tujuh faktor yang terdiri dari lingkungan kerja, kepemimpinan, hubungan tim dan rekan kerja, pelatihan dan pengembangan karir, kompensasi, kebijakan organisasi, dan kesejahteraan di tempat kerja. Metode penelitian ini adalah penelitian kuantitatif dengan jenis penelitian deskriptif dan analisis faktor. Responden penelitian berjumlah 83 karyawan di PT. ABC Bandung dengan pengambilan sampel menggunakan teknik Simple Random Sampling dan teknik analisisnya menggunakan metode analisis faktor dengan bantuan SPSS Versi 25. Hasil penelitian menunjukkan tingkat employee engagement pada karyawan di PT. ABC Bandung sebesar 71,05\%, sehingga dapat disimpulkan bahwa tingkat employee engagement di PT. ABC Bandung dalam kategori tinggi. Penelitian ini menghasilkan satu faktor baru yaitu Faktor Keterlibatan Karyawan dengan variabel kontribusi terbesarnya adalah lingkungan kerja.

\section{A B S T RAC T}

Employee engagement is a form of employee loyalty to the company. This research was conducted at PT. ABC Bandung. There is an indication that there is a high level of employee engagement towards the employees of PT. ABC Bandung. Therefore, the aim of this study is to determine employee enagagement factors for the employees of PT. ABC Bandung. The factors of employee engagement in this study refer to the results of the research proposed by Anitha (2014) with the theoretical foundation of Elliott and Corey (2018: 13). In Anitha's study (2014) there were seven factors consisting of work environment, leadership, team and co-worker relationship, training and career development, compensation, organizational policy, and workplace well-being. This research method is quantitative research with descriptive research and factor analysis. The research respondents were 83 employees of PT. ABC Bandung by sampling using Simple Random Sampling method and factor analysis using SPSS Version 25. The results showed the level of employee engagement on employees at PT. ABC Bandung at $71.05 \%$, so it can be concluded that the level of employee management at PT. ABC Bandung in the high category. This research produces one new factor, namely the Employee Engagement Factor with the biggest contribution variable is the work environment.

Copyright (C) Ekuitas: Jurnal Pendidikan Ekonomi. All rights reserved.

\footnotetext{
* Corresponding author.

E-mail : irmameilina@gmail.com (Ni Putu Irma Mei Lina)

$\underline{10.23887 / \text { ekuitas.v7i2.17233 }}$
} 


\section{Pendahuluan}

Sumber daya manusia merupakan salah satu faktor penting dalam pembangunan suatu perusahaan/organisasi. Oleh karena itu sumber daya manusia harus dikelola dengan baik untuk meningkatkan efektivitas dan efisiensi dalam mencapai tujuan organisasi.

Employee engagement telah menjadi tantangan utama secara global. Oleh karena itu, menjadi semakin penting bagi organisasi untuk menarik, melibatkan, mengembangkan, dan membangun kesetiaan di antara karyawan mereka untuk mendapatkan keunggulan kompetitif di pasar global saat ini.

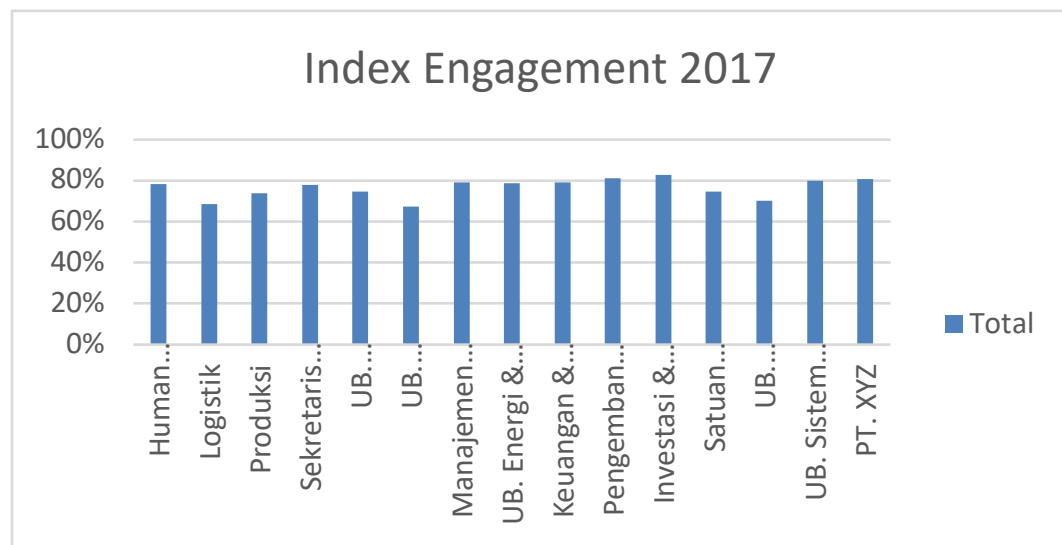

Gambar 1 Grafik Employee Engagement PT. ABC tahun 2017

Sumber : Divisi Sumber Daya Manusia dan Umum PT. ABC

Berdasarkan pada gambar 1 di atas total rata-rata employee engagement pada PT. ABC tahun 2017 adalah 76\%. Berdasarkan hal tersebut dapat dilihat nilai tingkat employee engagement di PT. ABC masuk kedalam kategori tinggi. Terkait dengan employee engagement, berdasarkan data yang didapat dari Divisi Sumber Daya Manusia dan Umum PT. ABC selama tahun 2018 telah dilakukan beberapa hal, diantaranya adalah 85 program pelatihan. Selain itu terdapat program pembekalan bagi karyawan yang telah memasuki masa persiapan pensiun dilaksanakan secara rutin setiap tahun sebagai bentuk perhatian perusahaan kepada para karyawan yang akan segera memasuki fase purna bakti dengan memberikan materi pelatihan khusus untuk membantu kesiapan mereka menghadapi masa pensiun. Pada tahun 2018 terdapat 13 karyawan yang memasuki masa persiapan pensiun. Selain program pelatihan perusahaan juga memberikan kesempatan kepada karyawan untuk mendapatkan beasiswa melanjutkan pendidikan.

Kebijakan dan prosedur organisasi yang sangat baik sangat penting untuk employee engagement dan pencapaian tujuan bisnis. Pada PT. ABC kebijakan pelaksanaan ketenagakerjaan, kesehatan dan keselamatan kerja mengacu kepada Peraturan pemerintah Republik Indonesia No. 50 Tahun 2012 tentang Sistem Manajemen Keselamatan dan Kesehatan Kerja. Selain itu kebijakan mengenai ketenagakerjaan juga tertuang dalam Perjanjian Kerja Bersama (PKB) 2017-2019 yang merupakan kesepakatan antara majemen PT. ABC dengan Ikatan Karyawan PT. ABC. Dalam mencapai target dan produktivitas yang optimal, PT. ABC telah menciptakan lingkungan kerja yang aman, nyaman, dan sehat. Berdasarkan wawancara pada tanggal 1 November 2018 kepada 15 karyawan, dapat diketahui bahwa mayoritas karyawan merasa senang bekerja di PT. ABC dikarenakan lingkungan kerja yang nyaman dan sesuai dengan tujuan dari masing-masing karyawan. Employee engagement terjadi secara alami saat para pemimpin memberi inspirasi. Berdasarkan wawancara pada tanggal 16 Januari 2018 kepada 15 karyawan, dapat diketahui bahwa mayoritas karyawan merasa bahwa pemimpin mereka mendukungnya untuk mengajukan gagasan-gagasan serta memberikan contoh standar moral yang baik. Kemudian karyawan yang memiliki hubungan baik dengan rekan kerjanya memiliki tingkat employee engagement yang tinggi. Sementara itu berdasarkan wawancara pada tanggal 16 Januari 2018 kepada 15 karyawan, dapat diketahui bahwa antar karyawan di PT. ABC memiliki hubungan baik dan saling mendukung satu sama lain.

Dalam rangka meningkatkan memelihara dan meningkatkan kesejahteraan bagi para karyawannya sesuai dengan ketentuan perundangan yang berlaku. PT ABC mengharapkan peningkatan kesejahteraan berupa materiil dan immateriil akan memberikan motivasi kepada karyawan untuk meningkatkan prestasi dan produktifitas karyawan serta memastikan tercapainya target kinerja karyawan dan sebagai salah satu cara untuk menjaga kualitas serta produktivitas kerja karyawan. Ada banyak keuntungan employee engagement diantaranya dapat meningkatkan retensi, kesetiaan karyawan, meningkatkan kinerja dan produktivitas untuk memberikan keunggulan kompetitif, serta meminimalkan 
turnover intention dan memaksimalkan semangat mereka. Selama tahun 2017, dari keseluruhan pegawai sebanyak 484 orang yang memilih berhenti bekerja dari PT. ABC selain dikarenakan pesiun adalah 2 orang.

Dengan fenomena tersebut, penulis tertarik untuk menganalisis faktor-faktor employee engagement pada perusahaan PT. ABC. Berdasarkan hal-hal yang telah diuraikan diatas, maka penulis melakukan penelitian dengan judul "Analisis Faktor-Faktor Penentu Employee Engagement di PT. ABC Bandung". Berdasarkan latar belakang diatas, maka tujuan pada penelitian ini adalah sebagai berikut, yang pertama, untuk mengetahui bagaimana employee engagement pada karyawan di PT. ABC dan yang kedua, untuk mengetahui faktor apa saja yang dominan sebagai penentu employee engagement pada karyawan di PT. ABC.

Faktor-Faktor Employee Engagement, menurut Elliott \& Corey (2018) Terdapat 10 elemen dalam Engagement Bride. Pertama, terdapat open and honest communication, yang merupakan Komunikasi yang terbuka dan jujur adalah dasar dari employee engagement karena hubungannya dengan kepercayaan. Ini akan membutuhkan kerja dan komitmen di semua tingkatan manajemen. Untuk membangun budaya kepercayaan tinggi, harus memberi ruang bagi perbedaan pendapat, ketidaksetujuan, dan keragaman pendapat. Perusahaan terbaik mengembangkan budaya transparansi lateral di seluruh perusahaan antara rekan dan departemen. Kedua, terdapat purpose, mission and values dimana setiap Perusahaan memerlukan misi yang menginspirasi dan otentik serta nilai-nilai yang layak huni yang mendukung dan mendorong bisnis dan karyawan. Purpose, mission \& values yang jelas dan dikomunikasikan dengan baik menginspirasi karyawan, menghubungkan pelanggan dan menciptakan keselarasan. Ketidaksejajaran antara kata dan tindakan tidak autentik, dan bisa menjadi kunci pelepasan.

Ketiga, Leadership, Dunia sedang berubah, teknologi adalah kekuatan yang mendemokratisasi dan para pemimpin harus melayani rakyat mereka lebih dari sebelumnya. Para pemimpin dulu dipekerjakan dan dipecat oleh bos mereka. Sekarang, jika mereka kehilangan rasa hormat, mereka dapat ditolak oleh orang-orang yang mereka pimpin. Semua perusahaan dengan engagement tertinggi memiliki keterlibatan yang diperjuangkan di tingkat CEO. Keempat, Management, Kebijakan dan praktik manajemen harus sejalan dengan nilai-nilai dan apa yang dikatakan kepemimpinan akan memiliki budaya yang tidak otentik. Memperlakukan karyawan sebagai musuh, yang merupakan awal dari banyaknya buku pegangan karyawan dan dokumen kebijakan, merupakan faktor kunci dalam merusak kepercayaan. Mungkin kebohongan terbesar yang kita miliki dalam praktik manajemen adalah mitos bahwa pekerjaan itu permanen tidak berurusan dengan ini merusak hubungan manajemen. Manajer sangat kuat dan sangat penting bagi mereka untuk bergabung dengan keterlibatan karyawan.

Kelima, job design, Desain pekerjaan yang buruk dapat menyabotase peluang employee engagement. Beberapa pekerjaan terlalu mudah untuk dilibatkan karena mereka tidak memiliki otonomi dan kebebasan. Pekerjaan yang dirancang terbaik memiliki pengakuan dan pembelajaran sejak awal. Masalah desain pekerjaan sebenarnya bisa menjadi akar penyebab masalah dengan pengakuan. Keenam, Learning Teknologi telah secara mendasar mengubah pembelajaran dengan menyediakan sejumlah besar konten gratis. Belajar adalah investasi pribadi itu harus dimiliki oleh individu, memberi mereka kebebasan untuk belajar di waktu mereka sendiri, dengan kecepatan mereka dan dengan syarat mereka. Agar pembelajaran terjadi, perusahaan harus terlebih dahulu memiliki budaya belajar, menginspirasi, dan mendorong pembelajaran. Desain dan budaya kerja adalah kunci tanpa kebebasan dan tanggung jawab, tidak ada pembelajaran.

Ketujuh, recognition, Dari uang yang dihabiskan untuk pengakuan karyawan, $87 \%$ dihabiskan untuk pengakuan kepemilikan semuanya terbuang sia-sia. Sebagian besar perusahaan melumpuhkan program mereka dengan struktur yang rumit, alur kerja dan proses persetujuan yang membatasi kemampuan orang untuk hanya mengucapkan terima kasih. Agar efektif, pengakuan harus berkelanjutan, tepat waktu, adil, relevan, dan pribadi. Ini adalah pemikiran yang diperhitungkan setiap saat; uang dan hadiah adalah hadiah kedua. Manajer dan karyawan perlu pelatihan dan pelatihan untuk dapat sering mengucapkan "terima kasih" dan tanpa rasa takut. Kedelapan, pay and benefit, Banyak masalah dengan gaji adalah tentang keadilan. Bayaran jarang bersifat pribadi dan menjadi kurang demikian, yang berarti ketidakadilan terungkap lebih sering dan lebih cepat dari sebelumnya. Uang tunai adalah cara termahal untuk membayar seseorang. Tunjangan yang efektif harus memperkuat uang perusahaan.

Kesembilan, wellbeing, ruang kerja fisik dan virtual adalah enabler dan penghancur employee engagement. Ketika pekerjaan menjadi lebih bervariasi, ruang kerja telah mengambil peran yang lebih penting dan strategis dalam employee engagement. Jika ruang kerja kita benar-benar "bekerja," kita perlu mempertimbangkan bahwa pekerjaan dilakukan dengan cara yang berbeda oleh orang yang berbeda untuk mencapai tujuan yang berbeda. Membangun ruang kerja yang bagus membutuhkan keberanian dan komitmen untuk memperbarui praktik kerja. Kesepuluh, terdapat workspace, kesejahteraan membutuhkan 
pendekatan terpadu yang mencakup kesehatan fisik, keuangan, dan mental agar efektif. Teknologi telah secara fundamental mengubah hubungan antara rumah dan pekerjaan, dan kesalahan kita dalam mengatasi hal itu telah menyebabkan rekor tingkat stres. Bekerja fleksibel dalam kondisi saat ini tidak fleksibel. Mengatasi akar penyebab masalah kesejahteraan akan membutuhkan dukungan penuh dari seluruh organisasi.

Menurut Anitha (2014), terdapat tujuh faktor kunci yang mendorong employee engagement. Pertama, lingkungan kerja, manajemen yang menumbuhkan lingkungan kerja yang mendukung biasanya menunjukkan perhatian untuk kebutuhan dan perasaan karyawan, memberikan umpan balik positif dan mendorong mereka untuk menyuarakan keprihatinan mereka, untuk mengembangkan keterampilan baru dan untuk memecahkan masalah yang berhubungan dengan pekerjaan. Lingkungan tempat kerja yang berarti akan membantu karyawan untuk fokus pada pekerjaan dan kerukunan antarpribadi sehingga dianggap sebagai penentu utama employee engagement. Kedua, kepemimpinan. Kepemimpinan merupakan kriteria utama kedua yang diidentifikasi sebagai faktor fundamental untuk menginformasikan employee engagement. Kepemimpinan yang efektif adalah konstruksi multi-dimensi tingkat tinggi yang terdiri dari kesadaran diri, pemrosesan informasi yang seimbang, transparansi relasional, dan standar moral yang diinternalisasi. Employee engagement terjadi secara alami saat para pemimpin memberi inspirasi. Pemimpin bertanggung jawab untuk mengkomunikasikan bahwa usaha karyawan memainkan peran utama dalam kesuksesan bisnis secara keseluruhan. Faktor kepemimpinan yang diukur terdiri dari indikator kepemimpinan yang efektif dan dukungan pemimpin yang dirasakan.

Ketiga, terdapat hubungan tim dan rekan kerja, hubungan tim dan rekan kerja adalah aspek lain yang secara eksplisit menekankan aspek harmoni interpersonal dari employee engagement. Menurut Kahn bahwa hubungan interpersonal yang mendukung dan saling percaya, serta tim pendukung, mempromosikan employee engagement. Lingkungan yang terbuka dan mendukung sangat penting bagi karyawan untuk merasa aman di tempat kerja dan terlibat sepenuhnya dengan tanggung jawab mereka. Locke dan Taylor berpendapat bahwa individu yang memiliki interaksi interpersonal positif dengan rekan kerja mereka juga harus mengalami makna yang lebih besar dalam pekerjaan mereka. Jadi jika karyawan tersebut memiliki hubungan baik dengan rekan kerjanya, diharapkan memiliki tingkat employee engagement yang tinggi. Keempat, pelatihan dan pengembangan karir, pelatihan dan pengembangan karir merupakan dimensi penting lainnya dipertimbangkan dalam proses employee engagement karena membantu karyawan untuk berkonsentrasi pada dimensi kerja yang terfokus. Pelatihan meningkatkan akurasi layanan sehingga berdampak pada kinerja layanan dan employee engagement. Ketika karyawan menjalani program pengembangan pelatihan dan pembelajaran, kepercayaan dirinya meningkat di bidang pelatihan yang dapat memotivasi mereka untuk lebih terlibat dalam pekerjaan mereka.

Kelima, kompenasasi dan remunerasi. Kompensasi adalah atribut yang sangat diperlukan untuk employee engagement yang memotivasi seorang karyawan untuk mencapai lebih kemudian akan lebih terfokus pada pekerjaan dan pengembangan pribadi mereka. Kompensasi terdiri dari penghargaan finansial dan non-finansial seperti skema liburan dan voucher ekstra. Tingkat employee engagement adalah fungsi dari persepsi mereka tentang manfaat yang mereka terima. Oleh karena itu penting bagi manajemen untuk menyajikan standar remunerasi dan pengakuan yang dapat diterima bagi karyawan mereka, jika mereka ingin mencapai tingkat employee engagement yang tinggi. Keenam, yaitu kebijakan, prosedur, struktur, dan Sistem Organisasi. Kebijakan, prosedur, struktur, dan sistem organisasi menentukan sejauh mana karyawan terlibat dalam sebuah organisasi. Kebijakan dan prosedur organisasi yang baik sangat penting untuk employee engagement dan pencapaian tujuan bisnis. Kebijakan dan prosedur penting mencakup rekrutmen dan seleksi yang adil, flexi-timing (waktu luang), bantuan dalam menyeimbangkan pekerjaan dan kehidupan, serta kebijakan promosi yang adil. Ketujuh, kesejahteraan di tempat kerja. Kesejahteraan di tempat kerja merupakan tindakan holistik yang meningkatkan employee engagement. Pendorong employee engagement yang paling penting adalah ketertarikan manajemen senior terhadap kesejahteraan karyawan. Perceived Organisation Support tercakup dalam variabel ini.

Kerangka Pemikiran, penelitian ini merujuk pada hasil penelitian yang dikemukakan oleh Anitha (2014) dengan landasan teori dari Elliott \& Corey (2018). Alasannya karena faktor-faktor tersebut telah diidentifikasi dan diuji secara empiris terbukti merupakan faktor penentu employee engagement yang valid. Peneliti ingin mengkonfirmasi apakah faktor-faktor yang dikemukakan oleh Anitha (2014) juga merupakan faktor pendorong karyawan di PT. ABC dalam bekerja. Menurut Elliott \& Corey (2018) Dalam hal ini, ada sepuluh elemen engagement bride yang akan disesuaikan dengan tujuh faktor pendorong employee engagement menurut Anitha (2014). Pertama, yaitu open and honest communication termasuk ke dalam hubungan tim dan rekan kerja. Kedua, purpose, mission, and values dan management termasuk ke dalam kebijakan organisasi. Ketiga, kepemimpinan, Keempat, job design, learning, dan recognition 
termasuk ke dalam pelatihan dan pengembangan karir. Kelima, pay and benefit termasuk ke dalam kompensasi dan remunerasi. Keenam, wellbeing termasuk ke dalam kesejahteraan di tempat kerja. Ketujuh, dimana workspace termasuk ke dalam lingkungan kerja.

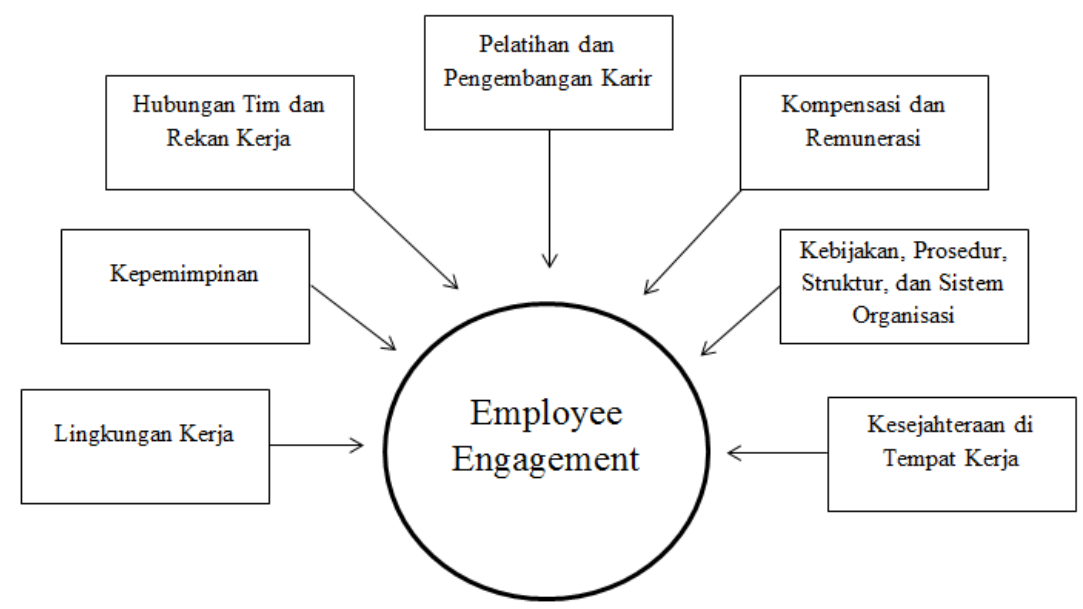

Gambar 2. Kerangka Pemikiran

Sumber: Anitha (2014)

\section{Hipotesis penelitian}

Berdasarkan latar belakang, identifikasi masalah, dan kerangka pemikiran sebelumnya, maka hipotesis dari penelitian ini adalah "Terdapat Faktor-Faktor Yang Membentuk Employee Engagement di PT. ABC Bandung".

\section{Metode}

Berdasarkan metodenya penelitian ini merupakan penelitian kuantitatif. Metode kuantitatif adalah metode penelitian yang berlandaskan pada filsafat positivisme, digunakan untuk meneliti pada populasi atau sampel tertentu, pengumpulan data menggunakan instumen penelitian, analisis data bersifat kuantitatif/statistik, dengan tujuan untuk menguji hipotesis yang telah ditetapkan.

Berdasarkan tujuan penelitian ini merupakan penelitian deskriptif. Statistik deskriptif adalah statistik yang digunakan untuk menganalisis data dengan cara mendeskripsikan atau menggambarkan data yang telah terkumpul sebagaimana adanya tanpa bermaksud membuat kesimpulan yang berlaku untuk umum atau generalisasi.

Berdasarkan alat ukur statistik penelitian ini menggunakan analisis faktor. Analisis faktor merupakan suatu analisis statistik yang berfungsi untuk mereduksi atau meringkas beberapa variabel yang saling independen menjadi lebih sedikit variabel.

\section{Hasil dan pembahasan}

Analisis Deskriptif, berdasarkan rekapitulasi persentase employee engagement karyawan di PT. ABC Bandung secara keseluruhan adalah sebesar $71,05 \%$ yang berada pada interpretasi nilai antara $68 \%$ $84 \%$. Kriteria penilaian persentase untuk nilai $71,05 \%$ termasuk dalam kategori tinggi. Selain itu, ratarata skor tertinggi sebesar $78,07 \%$ pada faktor Hubungan Tim dan Rekan Kerja yang berada pada interpretasi nilai antara 68\% - 84\% dan berada dalam kategori tinggi. Tim yang efektif dan hubungan rekan kerja yang sehat diperlukan untuk meningkatkan keterlibatan. Faktor-faktor termasuk bakat, iklim tim, kebanggaan kolektif, komitmen, kepemimpinan, tujuan, komunikasi, peningkatan berkelanjutan, etika tim dan ikatan tim membutuhkan perhatian khusus dari sudut pengusaha untuk meningkatkan hubungan tim dan rekan kerja. Oleh karena itu penting bagi organisasi untuk memfasilitasi hubungan rekan kerja yang ditingkatkan dan memberikan suasana di mana karyawan akan berkembang. Maka dapat disimpulkan bahwa PT. ABC Bandung telah memberikan fasilitas hubungan rekan kerja dan memberikan suasana agar karyawan dapat berkembang sehingga dapat meningkatkan employee engagement. 


\section{Analisis Faktor}

a. Menilai Variabel yang Layak

Tabel 1. KMO dan Bartlett's Test

\begin{tabular}{|c|c|c|}
\hline \multicolumn{2}{|c|}{$\begin{array}{l}\text { Kaiser-Meyer-Olkin Measure of Sampling } \\
\text { Adequacy. }\end{array}$} & .886 \\
\hline Bartlett's Test of & Approx. Chi-Square & 437.866 \\
\hline Sphericity & $\mathrm{Df}$ & 21 \\
\hline & Sig. & .000 \\
\hline
\end{tabular}

Sumber: hasil olah data peneliti

Tabel 1 menunjukkan KMO Measure of Sampling Adequacy adalah 0,886. Angka KMO > 0,5 menunjukkan bahwa kumpulan variabel faktor-faktor tersebut masih bisa diprediksi dan bisa dianalisis lebih lanjut menggunakan analisis faktor. Kemudian, dapat dilihat juga angka Bartlett's Test of Sphericity (diperlihatkan dengan angka Chi Square) sebesar 437,866 dengan signifikansi 0,000 yang artinya dapat dipercaya $100 \%$ bahwa antarvariabel terdapat korelasi karena nilai signifikansi jauh dibawah 0,05 $(0,000$ $<0,05)$.

Tabel 2. Anti Image Matriaces

\begin{tabular}{|c|l|c|}
\hline NO & \multicolumn{1}{|c|}{ FAKTOR } & MSA \\
\hline 1 & Lingkungan Kerja & 0,889 \\
\hline 2 & Kepemimpinan & 0,856 \\
\hline 3 & Hubungan Tim dan Rekan Kerja & 0,913 \\
\hline 4 & Pelatihan dan Pengembangan Karir & 0,857 \\
\hline 5 & Kompensasi dan Remunerasi & 0,896 \\
\hline 6 & Kebijakan Organisasi & 0,920 \\
\hline 7 & Kesejahteraan di Tempat Kerja & 0,880 \\
\hline
\end{tabular}

Sumber: Hasil Olah Data Peneliti

Tabel 2 menunjukkan nilai MSA dari masing-masing faktor. Faktor-faktor tersebut dapat dikatakan sebagai faktor pendorong employee engagement karyawan di PT. ABC Bandung apabila nilai MSA > 0,5. Dari masing-masing nilai MSA yang terlihat pada Tabel 4.10 menunjukkan semua faktor memiliki nilai MSA > 0,5 sehingga dapat melanjutkan analisis ke langkah berikutnya.

b. Proses Factoring dan Rotasi

Tabel 3. Communalities

\begin{tabular}{|l|r|r|}
\hline \multicolumn{1}{|c|}{} & Initial & Extraction \\
\hline Lingkungan Kerja & 1.000 & .846 \\
Kepemimpinan & 1.000 & .662 \\
Hubungan Tim dan Rekan Kerja & 1.000 & .414 \\
Pelatihan dan Pengembangan & 1.000 & .700 \\
Karir & & \\
Kompensasi dan Remunerasi & 1.000 & .665 \\
Kebijakan Organisasi & 1.000 & .779 \\
Kesejahteraan di Tempat Kerja & 1.000 & .783 \\
\hline
\end{tabular}

Extraction Method: Principal Component Analysis.

Pada Tabel 3 bisa dilihat bahwa variabel Lingkungan Keja memiliki nilai besaran tertinggi. Maka dapat disimpulkan bahwa variabel Lingkungan Kerja memiliki hubungan erat dengan faktor yang terbentuk dengan memiliki kontribusi sebesar $84,6 \%$ terhadap faktor yang terbentuk. Kemudian variabel yang memiliki nilai besaran terkecil adalah variabel Hubungan Tim dan Rekan Kerja yang memiliki kontribusi sebesar 41,4\% terhadap faktor yang terbentuk. 
Tabel 4. Total Variance Explained

\begin{tabular}{|c|c|c|c|c|c|c|}
\hline \multirow[b]{2}{*}{$\begin{array}{c}\text { Componen } \\
\mathrm{t}\end{array}$} & \multicolumn{3}{|c|}{ Initial Eigenvalues } & \multicolumn{3}{|c|}{$\begin{array}{l}\text { Extraction Sums of Squared } \\
\text { Loadings }\end{array}$} \\
\hline & Total & $\begin{array}{c}\% \text { of } \\
\text { Varianc } \\
\mathrm{e}\end{array}$ & $\begin{array}{c}\text { Cumulative } \\
\%\end{array}$ & Total & $\begin{array}{c}\% \text { of } \\
\text { Variance }\end{array}$ & Cumulative \% \\
\hline 1 & 4.849 & 69.275 & 69.275 & 4.849 & 69.275 & 69.275 \\
\hline 2 & .753 & 10.754 & 80.030 & & & \\
\hline 3 & .436 & 6.227 & 86.256 & & & \\
\hline 4 & .414 & 5.908 & 92.164 & & & \\
\hline 5 & .219 & 3.126 & 95.290 & & & \\
\hline 6 & .182 & 2.599 & 97.889 & & & \\
\hline 7 & .148 & 2.111 & 100.000 & & & \\
\hline
\end{tabular}

Extraction Method: Principal Component Analysis.

Total Variance Explained, digunakan untuk mengetahui banyaknya faktor yang terbentuk, faktor yang terbentuk memiliki nilai eigenvalues $\geq 1$. Dilihat dari tabel diatas diketahui bahwa hanya terdapat 1 faktor yang terbentuk dengan jumlah 4.849 dan variance 69,275\%, pada component ke-dua terdapat nilai eigenvalues $\leq 1$ maka proses faktoring berhenti pada component ke-dua.

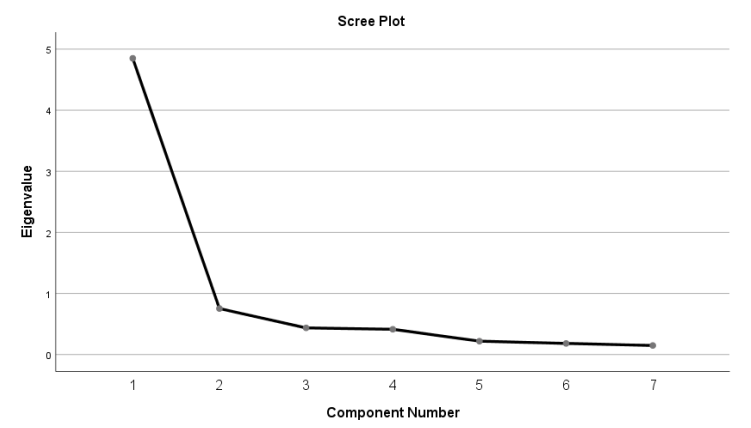

Gambar 2. Scree Plot

Sumber: hasil olah data peneliti

Terlihat gambar 2 bahwa dari 1 ke 2 faktor (garis sumbu component number dari 1 ke 2), arah garis menurun dengan drastis. Demikian pula dari ngka 1 ke 2 kini dengan slope yang lebih kecil. Pada faktor 2 sudah dibawah angka 1 dari sumbu Y (eigenvalues). Hal ini menunjukkan bahwa satu faktor yang paling mendominasi untuk meringkas ketujuh variabel tersebut. Hasil dari scree plot selalu sama dengan hasil Total Variance Explained untuk pembentukkan faktor dan keduanya bersifat saling melengkapi dalam pemberian informasi.

Tabel 5. Component Matrix

\begin{tabular}{|l|r|}
\hline & \multicolumn{1}{|c|}{ Component } \\
\cline { 2 - 2 } & \multicolumn{1}{|c|}{1} \\
Kingkungan Kerja & .920 \\
Hubungan Tim dan Rekan Kerja & .814 \\
Pelatihan dan Pengembangan Karir & .644 \\
Kompensasi dan Remunerasi & .837 \\
Kebijakan Organisasi & .815 \\
Kesejahteraan di Tempat Kerja & .883 \\
\hline
\end{tabular}

Extraction Method: Principal Component Analysis.

Terlihat dari tabel 5 iketahui bahwa tujuh faktor awal yang ada dan masuk dalam satu komponen, demikian halnya terbentuk satu faktor baru. Semua angka factor loadings ada dalam angka pembatas yaitu sebesar 0,5. Demikian pula sebuah faktor yang terbentuk sudah bisa mewakili semua variabel tersebut. Maka ke enam faktor tersebut tidak perlu melakukan rotasi faktor. 
Tabel 6. Faktor Loading

\begin{tabular}{|c|c|c|}
\hline No & Variabel Faktor & Faktor Loading \\
\hline 1 & Lingkungan Kerja & 0,920 \\
\hline 2 & Kesejahteraan di Tempat Kerja & 0,885 \\
\hline 3 & Kebijakan Organisasi & 0,883 \\
\hline 4 & Pelatihan dan Pengembangan Karir & 0,837 \\
\hline 5 & Kompensasi dan Remunerasi & 0,815 \\
\hline 6 & Kepemimpinan & 0,814 \\
\hline 7 & Hubungan Tim dan Rekan Kerja & 0,664 \\
\hline \multicolumn{2}{|c|}{ Sumber: Hasil data olahan peneliti } \\
\hline
\end{tabular}

Berdasarkan tabel 6 diatas diketahui bahwa Lingkungan Kerja memiliki jumlah 0,920, Kesejahteraan di Tempat Kerja memiliki jumlah sebesar 0,885, Kebijakan Organisasi memiliki jumlah 0,883, Pelatihan dan Pengembangan Karir memiliki jumlah yaitu 0,837, Kompensasi dan Remunerasi memiliki jumlah sebesar 0,815, Kepemimpinan memiliki jumlah sebesar 0,814 serta Hubungan Tim dan Rekan Kerja memiliki jumlah 0,664. Demikian pula dapat dilihat bahwa nilai yang paling besar adalah Lingkungan Kerja dengan nilai sebesar 0,920 atau 92\%.

\section{c. Penamaan Faktor (Labelling)}

Pada tahap ketiga analisis faktor ini setelah proses factoring dilakukan dan satu atau beberapa faktor terbentuk, kemudian kepada faktor tersebut diberi nama (identitas) tertentu yang dirasa tepat mewakili semua variabel yang ada pada faktor tersebut. Berdasarkan hasil pengolahan data factor loading dapat diketahui bahwa dari tujuh faktor awal yang ada, pada akhirnya terbentuk satu faktor baru yang dinamakan keterlibatan karyawan karyawan di PT.ABC Bandung yang meliputi sub faktor lingkungan kerja, kepemimpinan, hubungan tim dan rekan kerja, pelatihan dan pengembangan karir, kompensasi dan remunerasi, kebijakan organisasi, serta kesejahteraan di tempat kerja. Faktor ini dinamakan faktor-faktor yang mempengaruhi employee engagement karena di dalamnya jika dilihat dari factor loadings terdapat faktor-faktor yang sama-sama kuat dan tidak bisa dipisahkan satu dengan lainnya.

\section{Simpulan dan saran}

Kesimpulan, berdasarkan hasil penelitian dan analisis yang telah dilakukan, dapat diambil beberapa kesimpulan yang memberikan jawaban terhadap masalah yang dirumuskan dalam penelitian ini. Berdasarkan hasil kuesioner yang disebarkan kepada 83 responden karyawan di PT. ABC Bandung didapatkan kesimpulan sebagai berikut, Pertama, employee engagement karyawan di PT. ABC Bandung secara keseluruhan berada dalam kategori tinggi. Kedua, faktor baru yang diberi nama keterlibatan karyawan ini terdiri dari tujuh pembentuk faktor didalamnya, diantaranya: lingkungan kerja, kepemimpinan, hubungan tim dan rekan kerja, pelatihan dan pengembangan karir, kompensasi dan remunerasi, kebijakan organisasi, dan kesejahteraan di tempat kerja. Faktor penentu dominan sebagai faktor penentu employee engagement di PT. ABC Bandung adalah faktor lingkungan kerja. Hal tersebut menunjukkan bahwa faktor lingkungan kerja memiliki pengaruh yang kuat untuk meningkatkan employee engagement di PT. ABC Bandung.

Saran bagi penelitian selanjutnya, pada penelitian selanjutnya diharapkan dapat menggunakan sampel tidak hanya dari PT. ABC saja melainkan menggunakan sampel yang lebih luas, karena perluasan sampel akan mempengaruhi representasi keadaan penelitian yang sebelumnya. Sehingga hasil penelitian dapat juga dimanfaatkan secara lebih luas dan global dengan menggunakan penelitian dan teknik analisis data yang lebih kompleks lagi. Pada penelitian selanjutnya, diharapkan dengan faktor yang sama dapat mencari tahu faktor mana yang lebih berpengaruh dengan menggunakan analisis lain dan juga dapat menggunakan variabel yang lebih banyak dari berbagai macam teori daripada penelitian ini. Dengan menggunakan variabel yang sama, dilakukan pada perusahaan lain untuk melihat apakah faktor yang dominan akan sama atau tidak. Hal ini bertujuan untuk memperkaya pengetahuan terkait employee engagement pada organisasi.

\section{Daftar Rujukan}

Anitha J. (2014). Determinants of Employee Engagement and Their Impact on Employee Performance. International Journal of Productivity and Performance Management, Vol. 63 Issue: 3, 308-323.

Baroroh, A. (2013). Analisis Multivariat dan Time Series dengan SPSS 21. Jakarta: Elex Media Komputindo. 
Elliott, G., \& Corey, D. (2018). Build it The Rebel Playbook for World-Class Employee Engagement. United Kingdom: Wiley.

Gallup. (2013). State of the Global Workplace Report. USA: Gallup, Inc.

Lewiuci, P. G., \& Mustamu, R. H. (2016). Pengaruh Employee Engagement Terhadap Kinerja Karyawan Pada Perusahaan Keluarga Produsen Senapan Angin. AGORA Vol. 4, No. 2, 101-107.

Rao, M. S. (2017). Innovative Tools and Techniques to Ensure Effective Employee Engagement. Industrial and Commercial Training VOL. 49, 127-131.

Sugiyono. (2018). Metode Penelitian Kuantitatif . Bandung: Alfabeta.

Santoso, S. (2018). Mahir Statistik Multivariat dengan SPSS . Jakarta: Elex Media Komputindo.

Taneja, S., Sewell, S. S., \& Odom, R. Y. (2015). A Culture of Employee Engagement: A Strategic Perspective For Global Managers. Journal of Business Strategy, Vol. 36 Issue: 3, 46-56. 